\title{
METODOLOGIAS PARA DESENGRAXE DE RESÍDUO DA PRODUÇÃO DE GELATINA (COURINHO) E POSTERIOR DETERMINAÇÃO DAS SUAS PROPRIEDADES FUNCIONAIS
}

\author{
A. P. KEMPKA ${ }^{1}$, C. da CRUZ ${ }^{1}$, E. FAGUNDES ${ }^{1}$, G. POLMANN ${ }^{1}$, R.P. POMPERMAYER ${ }^{1}$, R. C. \\ PRESTES ${ }^{2}$ \\ ${ }^{1}$ Universidade do Estado de Santa Catarina, Departamento de Engenharia de Alimentos. \\ ${ }^{2}$ Universidade Federal de Santa Maria, Departamento de Tecnologia e Ciência dos Alimentos \\ E-mail para contato: aniela.kempka@udesc.br
}

\begin{abstract}
RESUMO - O processo de extração de colágeno para a obtenção de gelatina gera um resíduo sólido chamado de courinho, que se caracteriza por conter alto teor de proteína. $\mathrm{O}$ resíduo sólido contém ainda uma fração de proteína. Esta proteína pode ser utilizada na formulação de alimentos e deve possuir propriedades funcionais compatíveis com a matriz alimentar. $\mathrm{O}$ objetivo do presente trabalho foi testar 9 diferentes testes para o desengraxe do courinho e as propriedades funcionais do produto seco. Obteve-se $1 \%$ de gordura e $7 \%$ de proteína para o teste $\mathrm{T} 6\left(50{ }^{\circ} \mathrm{C}\right.$ durante $30 \mathrm{~min}$ com $\left.\mathrm{NaOH}\right)$. A menor extração de gordura foi obtida utilizando-se o teste $\mathrm{T} 7\left(20{ }^{\circ} \mathrm{C}\right.$, durante $30 \mathrm{~min}$ com $\mathrm{NaOH})$. As propriedades funcionais apresentaram diferenças quanto a solubilidade, com valores de 5,41\% (T8) a 8,13\% (T2) e para a capacidade de formação de espuma (T7 e T8 apresentaram formação). Para a capacidade de absorção de água e a capacidade de retenção de óleo não foi observada diferença estatística nos resultados.
\end{abstract}

\section{INTRODUÇÃO}

Tradicionalmente, o colágeno extraído para a produção de gelatina é isolado a partir da pele e de ossos de animais terrestres, como bovinos e suínos (Wang et al., 2014), sendo necessários diversos tratamentos químicos que objetivam sua extração e que podem ser determinantes na qualidade do colágeno e/ou gelatina obtidos. Para obtenção de colágeno a partir da pele suína, uma etapa fundamental a ser executada é a retirada da gordura (desengraxe) sendo, posteriormente, resfriada (Schrieber e Gareis, 2007; Gómez-Guillén et al., 2011).

Após o desengraxe, a pele suína segue para o tratamento com ácido ou base (diluídos). Neste tratamento, ocorre uma clivagem parcial das ligações cruzadas que mantém as cadeias de colágeno intactas. Além de ácidos e álcalis, enzimas ou uma combinação de enzimas e produtos químicos também são utilizadas para clivar as ligações cruzadas (Schrieber e Gareis, 2007; Prestes, 2013; Wang et al., 2014). Ao final desta etapa, o colágeno pode seguir para o pré-tratamento por processo ácido ou alcalino e posteriormente para extração, que consiste em um tratamento por 24 horas em ácido sulfúrico 2 a $4 \%$ a temperatura ambiente com ou sem auxílio da agitação mecânica. Após o tratamento ácido o pH é elevado pela adição de álcali. $\mathrm{Na}$ etapa de purificação, são realizadas a 


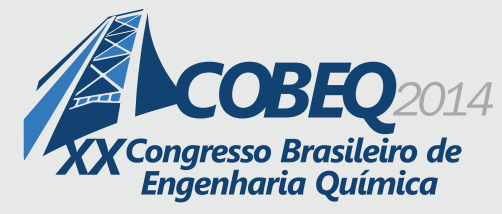

filtração e clarificação com objetivo de separar a gordura e sólidos da solução aquosa da gelatina (Prestes, 2013).

O resíduo sólido contém ainda uma fração de proteína. Esta proteína pode ser utilizada na formulação de alimentos e bebidas, porém, para que possa ser incorporada, é necessário que possua propriedades funcionais compatíveis com a matriz alimentar. A utilização de produtos proteicos pela indústria alimentícia tem mostrado aumento significativo em virtude de suas características funcionais. A capacidade que as proteínas possuem para desempenhar certas funções em determinado sistema alimentar, tais como, absorção de água, formação e estabilidade de emulsão, formação de gel e espuma, dentre outras, depende de numerosos fatores como conteúdo proteico, peptídeos, solubilidade, $\mathrm{pH}$, concentração de sal e métodos de processamento; fatores que afetam as propriedades funcionais das proteínas (Fontanari et al., 2007).

Entre as propriedades físicas e químicas que governam a funcionalidade das proteínas tem-se o tamanho, a forma, a composição e a sequência aminoacídica, o quociente hidrofobia/hidrofilia, as estruturas secundária, terciária e quaternária, o grau de flexibilidade-rigidez e a capacidade de interação com outros componentes como importantes (Fennema, 2000).

Portanto, o objetivo do presente trabalho foi testar nove diferentes metodologias buscando-se a remoção da gordura (desengraxe) presente no courinho e, após a secagem, determinar a capacidade de absorção de água, solubilidade, capacidade de retenção de óleo e capacidade de formação de espuma das amostras de courinho desengorduradas, secas e trituradas buscando-se a possibilidade de uso deste subproduto na formulação de alimentos e/ou bebidas.

\section{MATERIAS E MÉTODOS}

O resíduo da produção de gelatina, chamado courinho, foi fornecido pela indústria Gelnexunidade de Itá-SC, que processa pele suína para produção de gelatina.

\subsection{Testes de desengraxe}

Para o desengraxe do courinho, realizou-se 9 testes, mostrados na Tabela 1, definidos de acordo com ensaios prévios. Primeiramente, o courinho foi separado em 2 frações, sendo uma separada para o T1 e a outra, para os demais testes. A fração correspondente aos demais testes passou por um processo de lavagem com água a $20{ }^{\circ} \mathrm{C}$ durante 15 minutos, objetivando a retirada de gelatina remanescente, sendo utilizada para os testes T2 a T9. A amostra utilizada para o teste T1 não passou pelo processo de lavagem.

Em seguida, o courinho foi imerso em água contendo Hipoclorito de Sódio ou Hidróxido de Sódio nos volumes e temperaturas e mantidos de acordo com o tempo de cada teste. O teste T1 foi conduzido sem a adição de nenhum produto químico. 
Tabela 1 - Testes realizados para o desengraxe do courinho

\begin{tabular}{cccccc}
\hline Teste & \multicolumn{5}{c}{ Tratamento } \\
\cline { 2 - 6 } & $\begin{array}{c}\text { Volume de } \\
\text { água }(\mathbf{L} / \mathbf{k g} \\
\text { de courinho) }\end{array}$ & $\begin{array}{c}\text { Temperatura } \\
\left({ }^{\circ} \mathbf{C}\right)\end{array}$ & $\begin{array}{c}\text { Tempo } \\
(\text { minutos })\end{array}$ & Produto & $\begin{array}{c}\text { Quantidade } \\
(\mathbf{m L} / \mathbf{k g} \text { de } \\
\text { courinho) }\end{array}$ \\
\hline T1 & 3,2 & 80 & 15 & Sem produto & - \\
T2 & 3,2 & 20 & 30 & NaClO 12\% & 40 \\
T3 & 3,2 & 50 & 30 & NaClO 12\% & 40 \\
T4 & 3,2 & 80 & 30 & NaClO 12\% & 40 \\
T5 & 3,2 & 50 & 15 & NaClO 12\% & 20 \\
T6 & 3,2 & 50 & 30 & NaOH 2N & 20 \\
T7 & 3,2 & 20 & 30 & NaOH 2N & 10 \\
T8 & 3,2 & 50 & 30 & NaOH 2N & 10 \\
T9 & 3,2 & 80 & 15 & NaOH 2N & 10 \\
\hline
\end{tabular}

\subsection{Determinações físico-químicas e preparo das amostras}

Na caracterização físico-química determinou-se, o percentual de gordura, proteína, umidade e cinzas, sendo todas as metodologias de acordo com o Instituto Adolfo Lutz (2008) para a amostra bruta e para as amostras tratadas. As amostras provenientes de cada teste foram acondicionadas em bandejas de alumínio e dispostas em estufa com circulação de ar a temperatura de $105^{\circ} \mathrm{C} / 48$ horas para que ocorresse a secagem.

\subsection{Eficiência do desengraxe e rendimento da matéria prima}

Para o cálculo da eficiência do desengraxe e do rendimento da matéria prima, utilizou-se as Equações 1 e 2, respectivamente.

$$
\begin{gathered}
E D(\%)=1-\left(\frac{G_{f}}{G_{i}}\right) * 100 \\
R M(\%)=\left(\frac{M_{f}}{M_{i}}\right) * 100
\end{gathered}
$$

Onde: $M_{i}$ e $M_{f}$ são a massa inicial e final $(\mathrm{Kg})$ de amostra obtida antes e após os tratamentos; $G_{i}$ e $G_{f}$ são os percentuais de gordura antes e após os tratamentos.

\subsection{Propriedades funcionais}

Capacidade de Absorção de água (CAA): Utilizou-se a metodologia de Wang et al. (2006). Pesou-se $1,33 \mathrm{~g}$ da amostra adicionada a um tubo de centrífuga de $15 \mathrm{~mL}$ previamente pesado. 


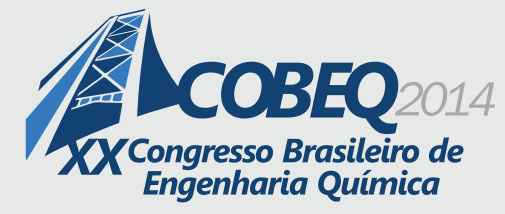

19 a 22 de outubro de 2014

Florianópolis/SC

Adicionou-se $8 \mathrm{~mL}$ de tampão $\mathrm{pH}$ fosfato de sódio $\mathrm{pH}$ 7. Esta mistura foi agitada por 30 segundos. $\mathrm{O}$ conteúdo permaneceu em repouso por 10 minutos e, em seguida, foi centrifugado a $2.300 \mathrm{rpm} / 25$ minutos. O sobrenadante foi esgotado e o tubo colocado inclinado (ângulo de $15^{\circ}$ a $20^{\circ}$ ) em estufa com circulação de ar (Orion) a $50^{\circ} \mathrm{C}$, durante 25 minutos. Após o resfriamento do tubo, este foi pesado e a CAA calculada em relação a $100 \mathrm{~g}$ de amostra.

Solubilidade: Para a obtenção da solubilidade, utilizou-se a metodologia de Liu et al. (2010) adaptada. Pesou-se 1,33 g de amostra que foi dispersa em solução tampão fosfato $\mathrm{pH} 7$. As misturas foram agitadas em Shaker a temperatura ambiente durante 30 minutos e centrifugadas a $3.000 \mathrm{rpm} / 15$ minutos. Após, retirou-se o sobrenadante e determinou-se o teor de proteína, sendo a solubilidade da

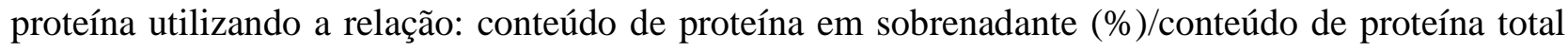
na amostra (\%), em percentual.

Capacidade de retenção de óleo (CRO): Para a determinação da CRO utilizou-se a metodologia de Wasswa et al. (2007). Pesou-se 0,5 g de amostra e adicionou-se $10 \mathrm{~mL}$ de óleo de soja em um tubo de centrífuga. Procedeu-se a mistura durante 30 segundos a $100 \mathrm{rpm}$. A dispersão de óleo foi centrifugada por 30 minutos/3.000 rpm. Determinou-se o volume de óleo separado sendo a CRO calculada como o $\mathrm{mL}$ de óleo absorvido/g de amostra.

Capacidade de formação de espuma (CFE): Soluções de amostra foram preparadas em tampão $\mathrm{pH} 7,0$ foram homogeneizadas com mixer doméstico durante 2 minutos. A amostra de espuma foi imediatamente transferida para uma proveta de $25 \mathrm{~mL}$ e o volume total lido após 30 segundos. A capacidade de formação de espuma foi calculada pela razão entre volume após batimento e o volume antes do batimento (Liu et al., 2010).

\section{RESULTADOS E DISCUSSÃO}

\subsection{Testes de desengraxe}

A Figura 1 mostra os perfis do percentual de gordura e do percentual de proteína da amostra sem tratamento (bruta) e das amostras obtidas nos 9 testes de desengraxe. Verifica-se que menor percentual de gordura foi para T6, seguido de T9, com $1 \%$ e $2 \%$, respectivamente. O teste onde se obteve o maior percentual de gordura foi T7 (10\%). Para a proteína, os maiores percentuais obtidos foram $19 \%$ para T3, seguidos de $18 \%$ para T2, T4 e T8. O menor percentual de proteína foi de $7 \%$ para T6. Para a umidade, os valores ficaram entre $77 \%$ (T1, T2 e T4) e $92 \%$ (T6). O teor de cinzas variou de $0,04 \%$ (T5) a $0,54 \%$ (T6).

Os testes com menor teor final de gordura consistiam em tratamentos com $\mathrm{NaOH}$ e a altas temperaturas. Nestes, também foram observados os menores teores de proteína e maiores teores de umidade. Para T6, não foi possível prosseguir com as análises propostas devido a característica do produto final: aspecto de gel e degradado. Contudo, observou-se que estas condições ( $\mathrm{NaOH}$ e altas temperaturas) podem agredir excessivamente o courinho. Já os tratamentos que apresentaram os maiores teores de gordura final foram o teste a frio aliado ao emprego de $\mathrm{NaOH}$ (T7), seguido do teste sem produto químico (T1). Isto pode indicar que o $\mathrm{NaOH}$ tem baixo potencial desengraxante 
para esta matéria-prima, sendo a temperatura o fator mais influente. Além disso, o baixo teor de proteína de $\mathrm{T} 7$ (13\%), assim como nos demais testes onde foi empregado o $\mathrm{NaOH}$, indica o quão este produto agride a matriz proteica da matéria prima.

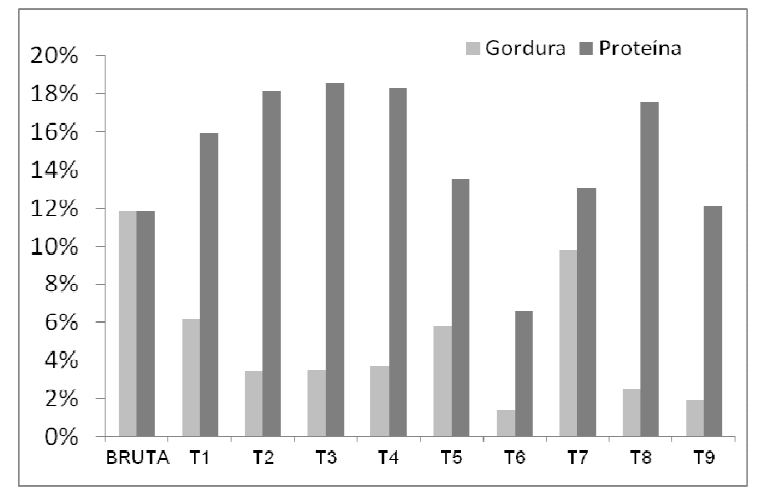

Figura 1: Percentuais de gordura e de proteína das amostras bruta e obtidas nos 9 testes de desengraxe

Os tratamentos realizados com $\mathrm{NaClO}$ apresentaram os maiores teores de proteína. Nestes, o emprego da temperatura não se mostrou vantajoso, visto que a eficiência do desengraxe foi praticamente a mesma em testes a frio (T2) e a quente (T3 e T4). Além disso, T2 apresentou maior rendimento de matéria prima em relação T3 e T4. A Figura 2 mostra os resultados para a eficiência de desengraxe e o rendimento da matéria prima.

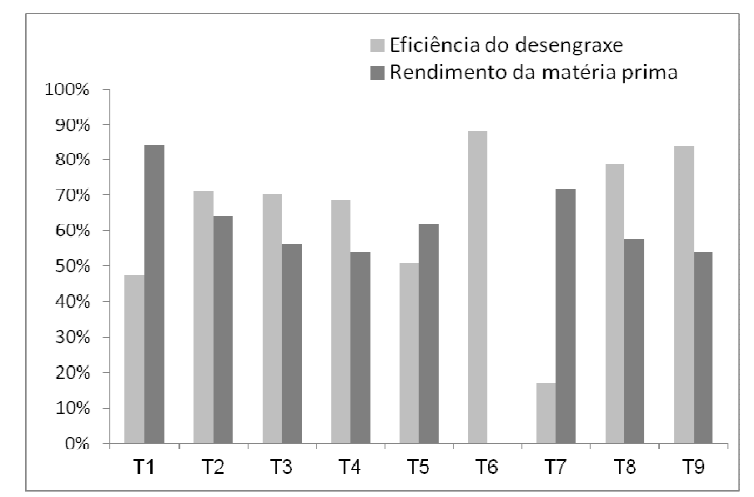

Figura 2: Eficiência de desengraxe e o rendimento da matéria prima para os 9 testes

Para a eficiência do desengraxe, verifica-se que T6 apresentou o maior valor, sendo de $88 \%$, seguido de T9 (84\%) e T8 (79\%). Os menores valores de eficiência de desengraxe foram obtidos para T7 (17 \%), seguido de T1 (47\%) e T5 (51\%). Testes com NaOH e a temperaturas maiores (T6, T8 e T9), obtiveram maior eficiência, porém menores rendimentos de matéria prima e menores teores de proteína.

$\mathrm{O}$ teste $\mathrm{T} 2$, que foi realizado a frio $\left(20^{\circ} \mathrm{C}\right)$, com emprego de $\mathrm{NaClO}$, apresentou maior 


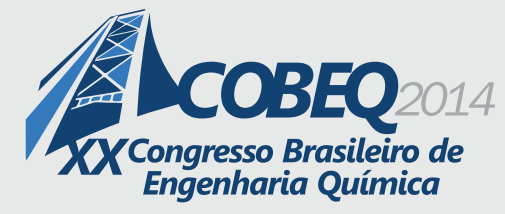

eficiência de desengraxe em relação a tratamentos onde foram empregadas temperaturas altas e maiores relações de produto químico por kg de matéria prima. Além disso, T2 apresentou rendimento de matéria-prima satisfatório e um dos maiores teores de proteína.

O T3 e T5 foram realizados a $50{ }^{\circ} \mathrm{C}$ e com $\mathrm{NaClO}$, porém em $\mathrm{T} 5$ foi empregado metade da relação de produto e metade do tempo de tratamento que em T3. Comparando ambos, observa-se que T5 obteve menor eficiência de desengraxe e maior rendimento de matéria prima que T3. A mesma relação pode ser observada comparando $\mathrm{T} 6$ e T8, ambos com NaOH. Considerando estes resultados, observa-se que a quantidade de produto químico potencializou o desengraxe, porém agrediu a matéria-prima, diminuindo seu rendimento.

Quanto aos valores de rendimento de matéria prima, que é a relação entre a massa sólida obtida no final dos testes de desengraxe e massa inicial utilizada antes do desengraxe, verifica-se que T1 apresentou maior valor, sendo $84 \%$, seguindo de T7 (72\%) e T2 (64 \%). O menor valor obtido de rendimento de matéria prima foi para $\mathrm{T} 3$ e $\mathrm{T} 9$, ambos com $54 \%$. O tratamento que gerou maior rendimento (T1) corresponde a um lavado que, embora a $80{ }^{\circ} \mathrm{C}$, ocorreu por metade do período de tempo em relação aos demais (15 minutos) e sem o emprego de produto químico. A intensidade dos tratamentos mostrou relação inversamente proporcional ao rendimento da matéria prima: para os demais testes, tratamentos a $20^{\circ} \mathrm{C}$ apresentaram maiores rendimentos que a $50{ }^{\circ} \mathrm{C}$, que por sua vez, apresentaram maiores rendimentos que a $80{ }^{\circ} \mathrm{C}$. Ainda dentro da ordem de temperatura, testes com hipoclorito apresentam maiores rendimentos comparados a tratamentos com soda.

\subsection{Propriedades funcionais do courinho obtido nos testes de desengraxe}

A Tabela 2 mostra as médias e o Teste de Tukey para as propriedades funcionais determinadas. Verifica-se que para a CAA e para a CRO, não houve diferença significativa nos dados $(\mathrm{p}>0,05)$. A capacidade de absorção de água.

Tabela 2: Médias e Teste de Tukey dos resultados das propriedades funcionais

\begin{tabular}{ccccc}
\hline Teste & CAA (\%) & Solubilidade (\%) & CRO (\%) & CFE (\%) \\
\hline T1 & $257,51^{\mathrm{a}} \pm 41,06$ & $6,21^{\mathrm{a}} \pm 1,02$ & $1,97^{\mathrm{a}} \pm 0,39$ & $\mathrm{NF}$ \\
T2 & $256,05^{\mathrm{a}} \pm 22,63$ & $8,13^{\mathrm{b}} \pm 0,56$ & $1,68^{\mathrm{a}} \pm 0,89$ & $\mathrm{NF}$ \\
T3 & $289,18^{\mathrm{a}} \pm 0,81$ & $6,01^{\mathrm{a}} \pm 0,31$ & $2,36^{\mathrm{a}} \pm 0,19$ & $\mathrm{NF}$ \\
T4 & $273,10^{\mathrm{a}} \pm 2,99$ & $6,38^{\mathrm{a}} \pm 0,00$ & $1,97^{\mathrm{a}} \pm 0,00$ & $0,25^{\mathrm{a}} \pm 0,00$ \\
T5 & $257,94^{\mathrm{a}} \pm 1,19$ & $7,09^{\mathrm{ab}} \pm 0,11$ & $1,90^{\mathrm{a}} \pm 0,10$ & $\mathrm{NF}$ \\
T7 & $247,49^{\mathrm{a}} \pm 7,69$ & $7,72^{\mathrm{ab}} \pm 0,14$ & $1,50^{\mathrm{a}} \pm 0,10$ & $2,56^{\mathrm{b}} \pm 0,17$ \\
T8 & $275,75^{\mathrm{a}} \pm 4,64$ & $5,41^{\mathrm{a}} \pm 0,17$ & $1,03^{\mathrm{a}} \pm 0,00$ & $2,32^{\mathrm{b}} \pm 0,17$ \\
T9 & $282,12^{\mathrm{a}} \pm 1,01$ & $6,92^{\mathrm{ab}} \pm 0,00$ & $1,04^{\mathrm{a}} \pm 0,02$ & $\mathrm{NF}$ \\
\hline
\end{tabular}

Médias seguidas de letras minúsculas diferentes, nas colunas, diferem em nível de $95 \%$ de confiabilidade $(\mathrm{p}<0,05)$ pelo Teste de Tukey. NF= não houve formação de espuma.

Segundo Fennema (2000) as interações hidrofílicas são de natureza exotérmica (impulsionadas pela entalpia) e as pontes de hidrogênio estão, em sua maioria, no interior da estrutura, permanecendo estáveis em uma ampla faixa de temperatura, o que pode justificar a mesma característica de CAA e 


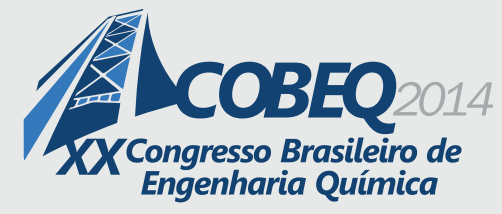

de CRO para todas as amostras. Ainda, o pH alcalino promove inchamento da matriz proteica, principalmente entre $\mathrm{pH} 9,0$ e 10,0, aumentando a absorção de água através dos espaços vazios gerados. Os testes foram conduzidos dentro desta faixa de $\mathrm{pH}$.

Para a solubilidade, houve diferença estatística significativa $(\mathrm{p}<0,05)$ para T8 e T2. Para T2, foi empregado temperatura de $20^{\circ} \mathrm{C}$ e hipoclorito de sódio, enquanto que para $\mathrm{T} 8$ foi empregado $50^{\circ} \mathrm{C} \mathrm{e}$ hidróxido de sódio. Em estudo com isolado de caseína láctea, proteína isolada de soja, e proteína animal hidrolisada, Soares et al.(2004), obtiveram valores de solubilidade de $80 \%$, $95 \%$ e $95 \%$, respectivamente.

A solubilidade das proteínas é determinada por um conjunto de características, tais como a massa molecular, a conformação estrutural e a flexibilidade, carga líquida e hidrofobicidade, além das suas interações com outros componentes alimentares (Soares et al., 2004). Interações hidrofílicas são mais estáveis a temperaturas mais baixas, enquanto as hidrofóbicas são instáveis (Fennema, 2000). Isto pode explicar a maior solubilidade de T2. Testes a $80{ }^{\circ} \mathrm{C}$ apresentaram maior solubilidade que testes a $50{ }^{\circ} \mathrm{C}$. Segundo Fennema (2000), o emprego de altas temperaturas aliadas a $\mathrm{pH}$ alcalino pode hidrolisar determinados grupos, aumentando a solubilidade da proteína. Em estudo realizado com concentrado proteico de girassol, Murate e Prudêncio-Ferreira (1999) verificaram que os tratamentos térmicos e mecânicos (agitação, extrusão) e a utilização de solventes puros ou em misturas com água desnaturam as proteínas diminuindo sua solubilidade.

Em relação a CFE, verificou-se a ocorrência desta propriedade apenas para T4, T7 e T8. Houve diferença significativa $(\mathrm{p}<0,05)$ de T4 para T7 e T8, sendo, os dois últimos iguais estatisticamente ( $>0,05)$. A geração de espuma foi considerada baixa. Possivelmente, a interferência de outros componentes, por exemplo, a gordura remanescente, pode ter influenciado a CFE. A presença de lipídios, especialmente fosfolipídios, em concentrações acima de $0,5 \%$ prejudica a formação de espuma, pois são mais tensoativos que as proteínas. Assim, se adsorvem rapidamente na interface e impedem a adsorção de proteínas, formando películas pouco coesas (Fennema, 2000).

A característica química da matriz proteica pode ter influenciado nas propriedades hidrofílicas e hidrofóbicas, visto que se trata de um resíduo de processo proveniente de tratamentos intensos. Porém, como os tratamentos realizados consistiram em simples desengraxe e moagem grosseira, verifica-se uma potencialidade no uso desta matéria prima em matrizes alimentares, por ter sido utilizada a o courinho bruto, apenas desengraxado e triturado (sem característica de pó). Possivelmente, menor granulometria do courinho bruto e/ou tratamentos específicos, tais como hidrólise enzimática, podem melhorar consideravelmente as propriedades funcionais, conforme observado em Soares et al., 2004; Takeiti et al., 2004; Fontanari et al., 2007; Liu et al., 2010 e Yeming e Tomotada, 2014.

\section{CONCLUSÃO}

Embora os tratamentos com altas temperaturas e emprego de produtos químicos tenham apresentado maior eficiência de desengraxe, o rendimento em matéria prima e o teor de proteína foram afetados. $\mathrm{O}$ tratamento sem produto químico a $80{ }^{\circ} \mathrm{C}$ (T1) apresentou resultado satisfatório 


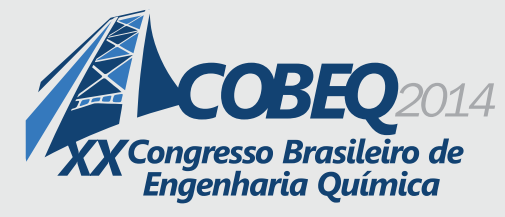

para teor de proteína, rendimento e desengraxe, sendo este o processo mais atrativo em termos de custo-benefício. Em relação às propriedades funcionais, foram observados bons resultados para capacidade de absorção de água, sem diferença significativa entre os tratamentos. Para as demais propriedades, não foram observados resultados satisfatórios. A desnaturação proteica devido ao excesso de tratamento, a granulometria do isolado podem ter comprometido as propriedades funcionais para o isolado do presente, porém, estudos devem continuar a serem feitos para o melhoramento destas propriedades além do uso da hidrólise enzimática.

\section{REFERÊNCIAS}

FONTANARI, G.G.; JACON, M.C.; PASTRE, I.A.; FERTONANI, F.L; NEVES, V.A., BATISTUTI, J.P. Isolado protéico de semente de goiaba (Psidium guajava): caracterização de propriedades funcionais. Ciênc. Tecnol. Aliment., v. 27(supl.), p.73-79, 2007.

GÓMEZ-GUILLÉN, M.C.; GIMÉNEZ, B.; LÓPEZ-CABALLERO, M.E. Functional and bioactive properties of collagen and gelatin from alternative sources: A review. Food Hydrocolloid, 25:18131827. (2011).

INSTITUTO ADOLFO LUTZ. Normas Analíticas do Instituto Adolfo Lutz. Métodos químicos e físicos para análise de alimentos, São Paulo: IMESP, 1985.

LIU, Q.; KONG, B.; XIONG, Y.L.; XIA, X. Antioxidant activity and functional properties of porcine plasma protein hydrolysate as influenced by the degree of hydrolysis. Food Chem., v.118, p. 403410, 2010.

MURATE, E. H.; PRUDENCIO-FERREIRA, S. H. Propriedades funcionais de concentrado proteico extrusado de sementes de girassol. Braz. Arch. Biol. Technol, v.42:2, 1999.

PRESTES R.C. Colágeno e seus derivados: Características e aplicações em produtos cárneos. UNOPAR Cientifica Ciências Biológicas e da Saúde, v.15:1, p. 65-74, 2013.

SCHRIEBER, R.; GAREIS, H. Gelatine Handbook: Theory and Industry Practice. Hardcover, (2007), 371p.

SOARES, L. H. de B.; ALBUQUERQUE, P. M.; ASSMANN, F; AYUB, M. A. Z. Physicochemical properties of three food proteins treated with transglutaminase. Cienc. Rural, v.34:.4, p. 1219-1223, 2004.

TAKEITI, C. Y; SOUZA, A. S.; NETTO, F. M. Influence of Heat Treatment on the Solubility and Emulsifying Properties of Soy Protein Isolate and its Enzyme Hydrolysates. Braz. J. Food Technol., v.7:1, p.87-101, 2004.

WANG, L.; LIANG, Q.; WANG, Z. XU, J.; LIU, Y.; MA H. Preparation and characterisation of type I and V collagens from the skin of Amur sturgeon (Acipenser schrenckii). Food Chem, 148:410-414, 2014.

WANG, S.H.; ROCHA, G.O.; NASCIMENTO, T.P.; ASCHERI, J.L.R. Absorção de água e propriedades espumantes de farinhas extrusadas de trigo e soja. Ciênc Tecnol Aliment., v.26:2, p.475481, 2006.

WASSWA, J.; TANG, J.; GU, X.; YUAN, X. Influence of the extent of enzymatic hydrolysis on the functional properties of protein hydrolysate from grass carp (Ctenopharyngodon idella) skin. Food Chem., v.104, p. 1698-1704, 2007.

YEMING, C.; TOMOTADA, O. Protein particle and soluble protein structure in prepared soymilk. Food Hydrocolloid, v. 39, p. 120-126, 2014. 